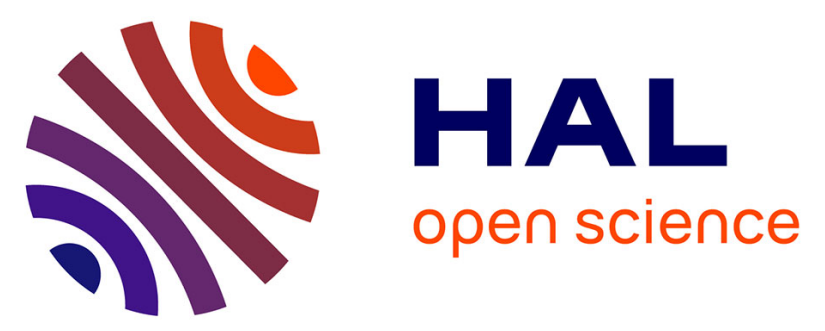

\title{
Application of X-ray microtomography to study the influence of the casting microstructure upon the tensile behaviour of an Al-Si alloy
}

N. Limodin, Ahmed El Bartali, Long Wang, J. Lachambre, Jean-Yves Buffiere, Eric Charkaluk

\section{To cite this version:}

N. Limodin, Ahmed El Bartali, Long Wang, J. Lachambre, Jean-Yves Buffiere, et al.. Application of $\mathrm{X}$-ray microtomography to study the influence of the casting microstructure upon the tensile behaviour of an Al-Si alloy. Nuclear Instruments and Methods in Physics Research Section B: Beam Interactions with Materials and Atoms, 2014, 324, pp.57-62. 10.1016/j.nimb.2013.07.034 . hal-00955455

\section{HAL Id: hal-00955455 \\ https://hal.science/hal-00955455}

Submitted on 23 Aug 2021

HAL is a multi-disciplinary open access archive for the deposit and dissemination of scientific research documents, whether they are published or not. The documents may come from teaching and research institutions in France or abroad, or from public or private research centers.
L'archive ouverte pluridisciplinaire HAL, est destinée au dépôt et à la diffusion de documents scientifiques de niveau recherche, publiés ou non, émanant des établissements d'enseignement et de recherche français ou étrangers, des laboratoires publics ou privés. 


\title{
Application of X-ray microtomography to study the influence of the casting microstructure upon the tensile behaviour of an Al-Si alloy
}

\author{
Nathalie Limodin $^{\mathrm{a}, *}$, Ahmed El Bartali ${ }^{\mathrm{a}, \mathrm{b}}$, Long Wang ${ }^{\mathrm{a}, \mathrm{b}}$, Joël Lachambre ${ }^{\mathrm{c}}$, Jean-Yves Buffiere ${ }^{\mathrm{c}}$, \\ Eric Charkaluk ${ }^{\mathrm{a}}$ \\ a Laboratoire de Mécanique de Lille (LML), CNRS, UMR 8107, Cité Scientifique, 59650 Villeneuve d'Ascq, France \\ ${ }^{\mathrm{b}}$ Ecole Centrale de Lille, 59650 Villeneuve d'Ascq, France \\ 'Laboratoire Matériaux, Ingénierie et Sciences (MATEIS), INSA-Lyon, CNRS, UMR 5510, 20 Av. Albert Einstein, 69621 Villeurbanne, France
}

In cast aluminium alloys used in the automotive industry the microstructure inherited from the foundry process has a strong influence on the mechanical properties. In the cylinder heads produced by the Lost Foam Casting process, the microstructure consists of hard intermetallic phases and large gas and micro-shrinkage pores. To study its influence, full field measurements at the microstructure scale were per-formed during a tensile test performed in situ under X-ray microtomography. Intermetallics were used as a natural speckle pattern. Feasibility of Digital Volume Correlation on this alloy was proved and the accuracy of the measurement was assessed and discussed in light of the small volume fraction of inter-metallics and in comparison with the accuracy of Digital Image Correlation performed on optical images at a finer spatial resolution.

\section{Introduction}

In the automotive industry, environmental considerations together with cost reduction requirements have led manufacturers to adopt a downsizing strategy, particularly for engine parts like cylinder heads. Thus, aluminium alloys and, recently, Lost Foam Casting process (LFC) were introduced to replace, respectively, cast irons and Die Casting (DC) process as a matter of geometry optimization, cost reduction and consumption control. However, aluminium alloy automotive parts produced by the LFC process have a coarser microstructure than parts produced with conventional casting processes at faster cooling rates. This coarse microstructure, which consists of hard second phase particles (eutectic Si, eutectic $\mathrm{Al}-\mathrm{Al}_{2} \mathrm{Cu}$, and iron based intermetallics), large pores and microshrinkage cavities, has a major influence on the fatigue properties. Although pores above a critical size play a decisive role by providing preferential crack initiation sites, an influence of oxides [17], iron-based intermetallics [13] and Si particles [2] is also observed. The fatigue behaviour of such a complex material is all the more difficult to study as cracks could initiate at any large defects present in bulk while the fatigue phenomenon although 3D

\footnotetext{
* Corresponding author. Tel.: +33 320335378.

E-mail addresses: nathalie.limodin@ec-lille.fr (N. Limodin), ahmed.elbartali@ ec-lille.fr (A. El Bartali), long.wang@ec-lille.fr (L. Wang), joel.lachambre@insa-lyon. fr (J. Lachambre), jean-yves.buffiere@insa-lyon.fr (J.-Y. Buffiere), eric.charkaluk@ ec-lille.fr (E. Charkaluk).
}

by nature is generally studied from the surface. In order to study the influence of the casting microstructure upon the fatigue behaviour of an $\mathrm{Al}-\mathrm{Si}$ alloy, an experimental protocol, which relies on the coupling of full field measurements at the microstructure scale, either in $2 \mathrm{D}$ or $3 \mathrm{D}$, with prior microstructural characterization of the specimen, has been set up and validated.

The present study will focus on the uncertainty analysis of the 3D displacement field measurements performed on X-ray microtomographic data as compared to 2D measurements.

\section{Experimental}

The material studied was a 356 aluminium silicon alloy (Al bal. - Si 6.61 wt.\% - Mg 0.30 wt.\% - Fe 0.11 wt.\% - Ti 0.10 wt.\%). Specimens (Fig. 1a) were cut out from two cylinder heads (in the fire deck area) by electro discharge machining. X-ray radiography was realized prior to the tensile test to screen the most suitable specimens, i.e. those presenting large defects away from the specimen's shoulders and with a maximum size of defects compatible with the specimen cross-section.

$\mathrm{X}$-ray microtomography was performed at the Mateis laboratory (Lyon, France) within a Computed X-ray Tomography (CT) system V-Tomex (Phoenix X-ray) fitted with a Nanofocus tube whose acceleration voltage can be adjusted from 10 to $160 \mathrm{kV}$. In the present work, a $80 \mathrm{kV}$ acceleration voltage was selected to ensure a $10 \%$ transmission of the X-ray beam through the crosssection of the sample. The specimen was placed on a rotating stage 


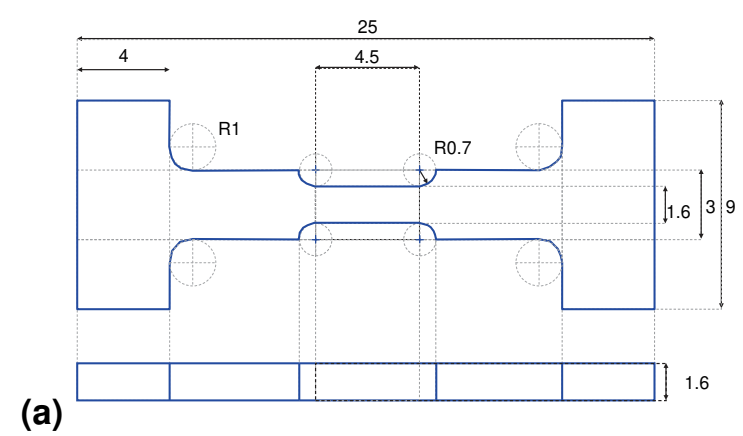

(b)

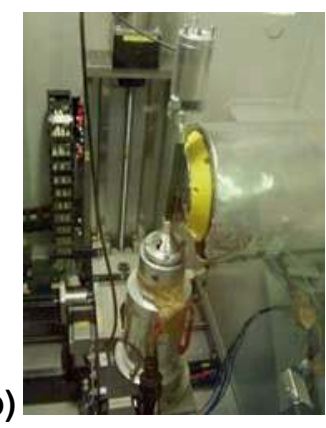

Fig. 1. (a) Specimen geometry (dimensions in $\mathrm{mm}$ ) and (b) in situ tensile rig used inside the lab-CT.

in the tomography chamber between the X-ray source and an amorphous $\mathrm{Si}$ diode array detector of dimensions $1920 \times 1536$ voxels. A set of 900 radiographs (scan) were taken while the sample was rotating over $360^{\circ}$ along its vertical axis. With an acquisition time per image of $500 \mathrm{~ms}$, one scan lasted about 45 min. A small in situ loading device (Fig. 1b) was used to load the specimen (see Ref. [3] for an overview of in situ test rigs available). Its main parts are a stepping motor at the bottom, a load cell at the top and a compression tube in-between. A stiff carbon tube (carbon twill surface) is used to transmit the load between the lower and upper parts of the rig as it fulfills the two requirements for lab-CT: the X-ray attenuation through the carbon tube is small and uniform throughout the scan acquisition and its diameter, which sets the specimen-to-source distance hence the magnification (divergent beam), could be as small as $10 \mathrm{~mm}$. The distance between the sample and the X-ray source could thus be reduced to $7.73 \mathrm{~mm}$ resulting in an image voxel size of $1.7 \mu \mathrm{m}$. This voxel size was chosen as a compromise between resolution and specimen size as higher resolution would require smaller, hence possibly less representative, specimens.

The aim was first to obtain 3D characterization of pores and iron intermetallic in the $\mathrm{A} 356 \mathrm{Al}-\mathrm{Si}$ alloy and then, to assess the feasibility of Digital Volume Correlation (DVC) for this alloy where natural markers are scarce. Thus scans were acquired at ten incremental loading tests before the specimen's failure at about $214 \mathrm{MPa}$. Reconstruction of the tomographic data was performed with a filtered back-projection algorithm using datos|x-acquisition software developed by Phoenix. It provides a 3D image with a 16 bit greyscale colormap that is proportional to the X-ray attenuation coefficient. Definition of a Region of Interest (ROI) that is focused on the crack reduced the image size to $900 \times 900 \times 900$ voxels $^{3}$.

In cast Al-Si alloys, X-ray tomography allows distinguishing between the aluminium matrix and $\mathrm{Cu} / \mathrm{Mg}$ rich phases or Fe intermetallic compounds [7] provided that the spatial resolution is small enough compared to the size of the microstructure [8].

In order to characterize the defects population, image analysis was performed in five samples with Image J software using the following procedure: (i) in order to reduce the amount of data, the images acquired at a $1.7 \mu \mathrm{m}$ voxel size were binned to a $3.4 \mu \mathrm{m}$ effective voxel size, (ii) a simple thresholding technique was used to segment the aluminium alloy and pores in the greyscale image. Quantitative analysis could then be realized with plugins developed by [1] in Image J software to label the pores, i.e. to attribute each individual pore a given label or color, and to measure several characteristics of the labelled pores. The pore's size was assessed from the largest edge of the bounding box enclosing the considered pore; it is thus close to the definition of a Feret diameter. Pores less than $2^{3}$ voxels in volume were assumed smaller than the image resolution and were hence neglected.

Displacement field measurements were then performed with CorreliC8 software [11] using an isotropic element with a 24 voxel edge for a region of interest of $768 \times 768 \times 768$ voxels $^{3}$ inside the original volume of $900 \times 900 \times 900$ voxels $^{3}$. The DIC method is well established for computing displacements and strains on the surface of samples or structures [12]. It consists in measuring displacement fields between image pairs of the same specimen at different loads. The displacement field is obtained, using the so-called brightness conservation, so that the image of the loaded sample is matched to the reference image when pixel locations are corrected for by the measured displacement field. Recent developments have made possible the extension of this technique to 3D displacement measurements in the bulk of specimens using 3D tomography images [11]. The resolution of this Digital Volume Correlation (DVC) technique depends directly on the presence of numerous and finely dispersed microstructural features inside the material. In a nodular cast iron, the fine dispersion of graphite nodules ( $14 \%$ in volume fraction), with a $45 \mu \mathrm{m}$ average diameter, was proved a valid texture for measuring 3D displacement fields around a propagating crack [9].

Besides, in order to study the surface damage micromechanisms at a fine microstructure scale, an experimental protocol was developed to obtain a natural surface suitable for image correlation without using a speckle pattern that will mask the microstructure. Once an appropriate colour etching [18] has been found, tensile tests on flat specimens were performed and a Questar long distance microscope was used for the in situ observation during tensile tests $[5,6]$.

\section{Results and discussion}

Fig. 2a shows a 3D rendering of the microstructure inside the specimen gauge length as observed with X-ray tomography at a voxel size of $1.7 \mu \mathrm{m}$. The microstructure inherited from casting at a slow cooling rate is coarse, i.e. Dendrite Arm Spacing (DAS) is about $79 \mu \mathrm{m}$, compared to the more standard $30 \mu \mathrm{m}$ DAS value for Die-Casting process. Therefore, the large intermetallics, rendered in purple in Fig. 2a, are detected although their morphology is not fully resolved and they could be used as a natural speckle for DVC in order to measure the 3D strain fields. The pores, either microshrinkage or gas porosity, are easily observed and quantified as shown in Fig. 2a. Fig. 2b shows the largest pores present in the volume.

In order to check the representativeness of the specimen, the size distribution of pores inside the scanned area of the tensile specimen $\left(3.8 \mathrm{~mm}^{3}\right)$ is analyzed and compared to the size distribution of pores in a larger population $\left(18 \mathrm{~mm}^{3}\right)$. Fig. 3a shows the size distribution of pores inside this tensile specimen compared to the same distribution obtained when considering the analysis performed over five specimens including this one. The specimen selected with X-ray radiography for the tensile test can be considered representative despite its small size. The volume fraction of pores amounts to $0.2 \%$ in the tensile specimen vs. $0.4 \%$ when 


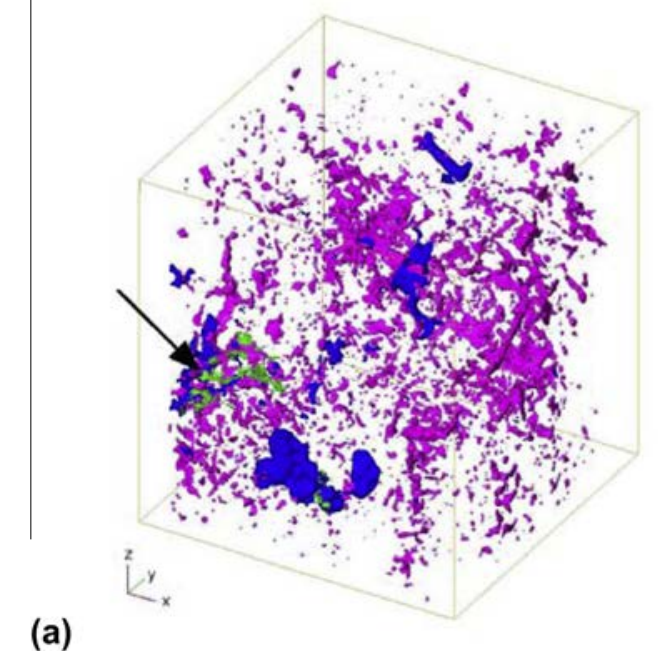

(b)
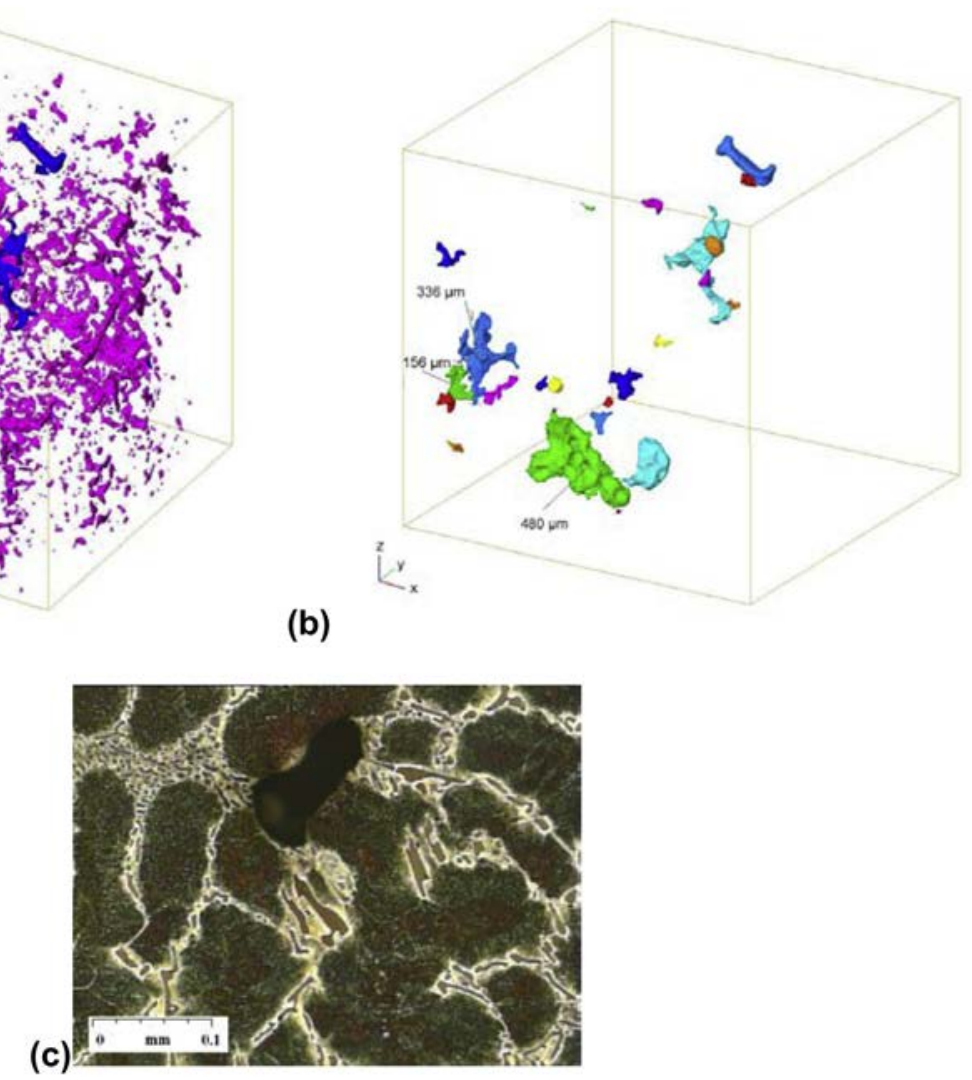

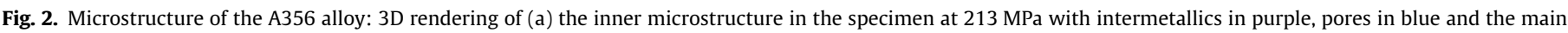

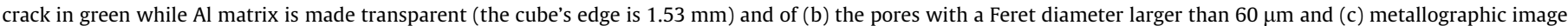
obtained after colour etching. (For interpretation of color in this Figure, the reader is referred to the web version of this article.)

considering a larger volume. As shown in Fig. 3a, the size distribution of pores presents one major peak centered on an average value of $40 \mu \mathrm{m}$. Different specimens with different studied volumes were observed to share this same characteristic peak, which accounts mainly for small rounded gas pores. However most of the pore volume fraction corresponds to a few large microshrinkage cavities for which the scatter from one sample to the other is important. To highlight this statement, Fig. $3 \mathrm{~b}$ shows the same size distributions as in Fig. 3a with volume fraction instead of density number along the $y$ axis. In the $18 \mathrm{~mm}^{3}$ volume, the total number of pores is 1104 and there are only five pores larger than $400 \mu \mathrm{m}$ but they represent more than half the total volume fraction of the pores population. In the present tensile specimen, the largest pore has a maximum Feret diameter of about $400 \mu \mathrm{m}$ while the maximum pore size is $1040 \mu \mathrm{m}$ when a larger volume is considered. Two conclusions could be drawn from the distributions in Fig. 3: (i) representativeness of the cast part might be difficult to obtain in the small scanned volume of a tomography sample and preliminary characterization should always be done to assess the "level of representativeness" of the specimen and (ii) the tail of the distribution is difficult to infer from a 2D metallographic analysis [14] which does not take into account the 3D nature of a pore and will thus lead to an underestimation of its real size.

In the present test, coalescence of two neighbouring pores, highlighted with an arrow in Fig. 2a, has led to progressive crack growth until final failure. Crack initiation under tensile loading was observed to occur not at the largest pore intersecting the surface in the specimen gauge length (in the right hand side of Fig. 2a) but at two smaller surface breaking tortuous microshrinkage cavities very close to each other. The effective Feret diameter of the adjacent pores, i.e. the addition of their respective sizes (336 and $156 \mu \mathrm{m}$ in Fig. 2b), is slightly larger than the size of the largest pore in the studied volume ( $480 \mu \mathrm{m}$ in Fig. $2 \mathrm{~b})$ while their cumulated volume is four times less than the largest pore volume. This underlines that the Feret diameter, which depends both on volume and morphology, is a more relevant parameter than the equivalent diameter, which depends solely on pore volume, to assess the harmfulness of a pore. Besides the pore shape should not be disregarded. The stress concentration effect of a pore and its distance to the free surface were indeed shown to have a strong correlation with crack initiation sites in [16,4].

Fig. 4 shows the displacement (a) and corresponding strain field (b) along the loading direction at the last loading step before failure, i.e. at $213 \mathrm{MPa}$; one half of the fractured sample has been scanned and its tomographic image has been registered to the reference image and superposed to the strain field to allow for comparison of the crack path with local deformation. The crack and pores, which are rendered in grey colour in Fig. $4 \mathrm{a}$, also correspond to the last loading step before failure. The main crack, initiated at the microshrinkage cavities shown in Fig. 2b, was detected in the tomographic image at an applied stress of $192 \mathrm{MPa}$ and then it was observed to grow with a further increase in the applied stress. A good correlation can be observed between strain localization and displacement discontinuity in the measured fields and the crack location at pores. Indeed, although the crack is not visible at the first loading step, a faint discontinuity at the crack location is already visible in the displacement field along the loading direction and this discontinuity intensifies as the load is increased. When the strain field along the loading direction (shown in Fig. 4(b)) is averaged over the whole volume, the global strain values at the different loading steps can be 

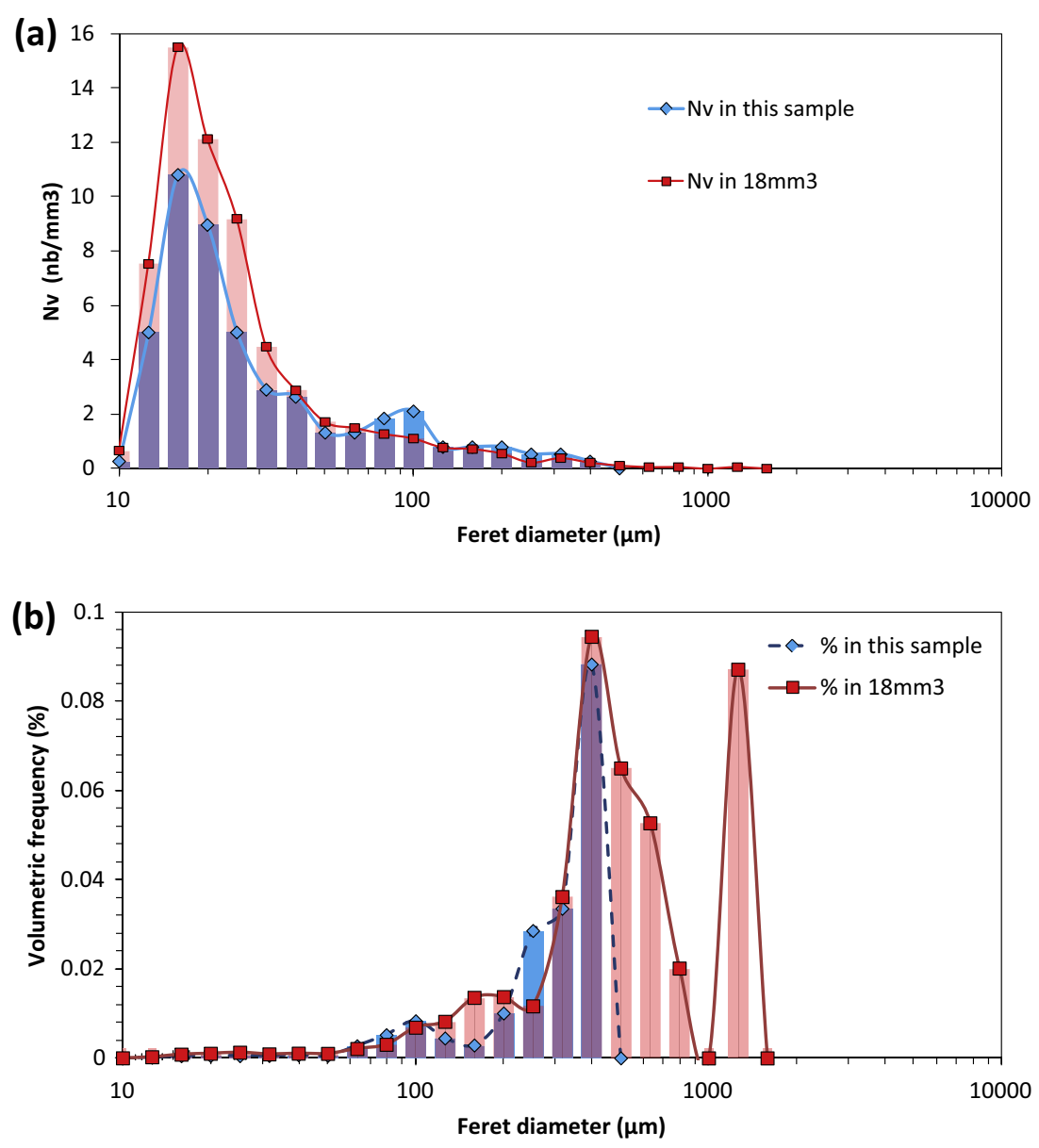

Fig. 3. Size distribution of pores in (a) number and (b) in volume fraction.

(a)

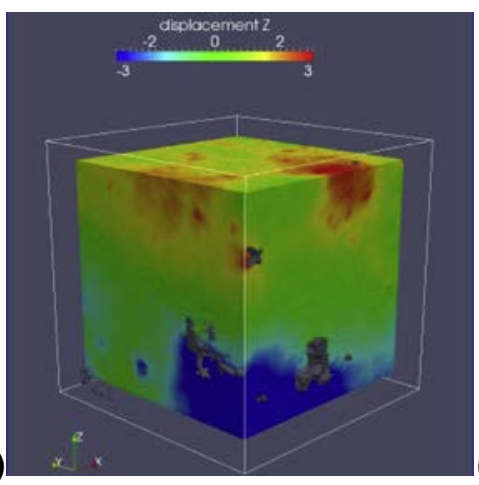

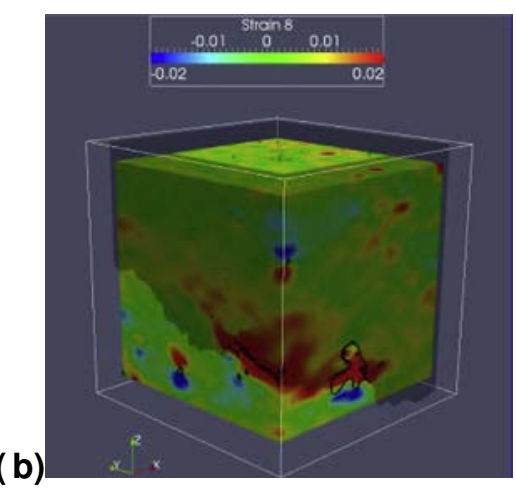

(c)

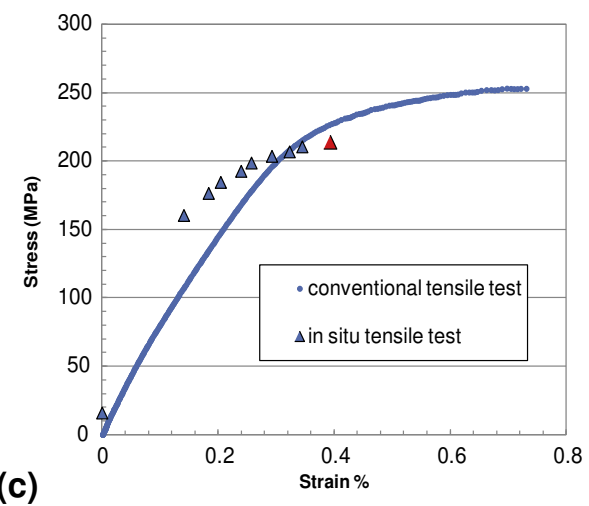

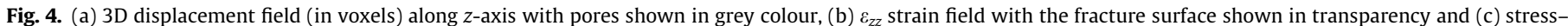
strain curves. (For interpretation of color in this Figure, the reader is referred to the web version of this article.)

used to draw the stress-strain curve in Fig. 4c. Compared to the stress-strain curve obtained from a tensile test realized on a larger specimen ( $5 \mathrm{~mm}$ diameter) with appropriate conventional strain measurement methods, i.e. with an extensometer, the stress-strain curve deduced from DVC ("in situ tensile test" in Fig. 4c) can be considered reliable although the large dispersion inherent to this defect possessing material makes the comparison uneasy. Besides the observed difference can certainly be associated to the small considered volume of material.

Usually, uncertainty of the displacement field in 2D is determined from the standard deviation of the displacement field computed between two images of the specimen: one at a reference position and one after a small shift, e.g. $10 \mu \mathrm{m}$ in the present case. In 3D, three shifts are needed to catch uncertainty in all directions. As the lab-CT X-ray beam is conical a translation along the beam direction will change the voxel size, e.g. from 1.7 to $1.695 \mu \mathrm{m}$ in the present case. This trick allows applying a known displacement field in all directions, i.e. a dilatation, which correspond to a maximum displacement of 1.5 voxel. The Fig. 5a shows that the uncertainty amounts to about 0.2 voxel $(0.36 \mu \mathrm{m})$ at a size of element of 24 voxels $(40.8 \mu \mathrm{m})$ for the 3D measurement. It is a fairly high value when compared to what was obtained in [10] for a 

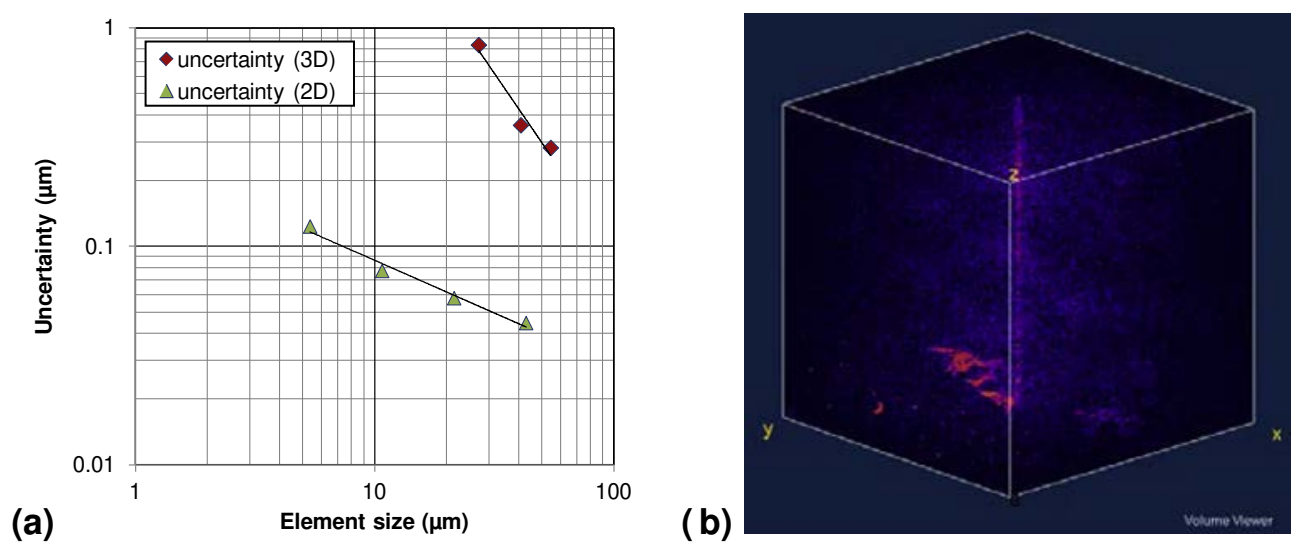

Fig. 5. (a) Uncertainty of the measured displacement field in 3D and 2D and (b) residual error of the 3D displacement field at $213 \mathrm{MPa}$.

nodular cast iron. The uncertainty of the 2D measurement varies from 0.13 to 0.37 pixel $(0.04-0.12 \mu \mathrm{m})$ for a size of element that varies from 16 to 128 pixels $(5.4-42.9 \mu \mathrm{m})$. As shown in Fig. 2c, colour etching enables to reveal Si segregation in the aluminium dendrites and gives a high spatial resolution. The spatial resolution of the measured displacement field in 2D is thus much higher than in $3 \mathrm{D}$ with an uncertainty that remains smaller than in $3 \mathrm{D}$ whatever the element size.

The results of the surface field measurements [6], although not reported here as we decided to focus on the measurement uncertainty, were indeed rather encouraging with, for example, strain localization at the locations of microcracks in the eutectic Silicon which were not observed at the resolution of the Questar image but with a Scanning Electron Microscope at the end of the test after specimen failure. The spatial resolution of surface field measurements seems difficult to achieve in 3D. The main reason must be the low volume fraction of natural markers in the bulk of the specimens. Considering that iron intermetallics are almost the sole detectable features, apart from porosity, and that their volume fraction amounts to about $0.7 \%$, the results obtained with DVC are encouraging. Although for high spatial resolution, the uncertainty of the 3D displacement field is about one decade higher than for 2D measurements, the strain localization at pores is well assessed although at a coarse resolution. The residual error, which is the difference between the reference image and the image of the loaded specimen "corrected" for by the displacement field measured with DVC, is maximum at the crack, which generates a discontinuity in the displacement field (see Fig. 4a) that avoids a perfect matching of the "corrected" image to the reference image, and helps reveal the crack's 3D shape in Fig. 5b. For the A356 alloy, DVC based on X-ray tomographic data obtained with a laboratory $\mathrm{X}$-ray source has potential applications to measure strain localization at the pores scale during a mechanical test. However, in order to obtain field measurement at smaller scales i.e. at intermetallics or at eutectic Si, which are not visible with lab-CT, surface field measurements performed on etched surface seem up to now the only possibility. The phase contrast, available with coherent synchrotron X-ray radiation, could help increase the spatial resolution of DVC measurements. Actually, it is expected that the use of phase contrast in addition to attenuation contrast will allow resolving the eutectic $\mathrm{Si}$, as reported in [15], in addition to the inclusions already visible by simple attenuation contrast.

\section{Conclusions}

The usefulness of X-ray microtomography to study the influence of the casting microstructure upon the mechanical properties of an Al-Si alloy has been proved. The 3D images, which were obtained at a $1.7 \mu \mathrm{m}$ voxel size at different loading steps, allowed identifying the pores as the main crack initiation sites in tensile loading. Then, in order to quantitatively analyze the strain localization at the 3D microstructure scale, intermetallics were used as a natural speckle pattern for DVC. Feasibility of DVC on this alloy was checked and the accuracy of the measurement was assessed and discussed in light of the small volume fraction of intermetallics and in comparison with the accuracy of 2D DIC realized on optic images at a finer spatial resolution.

The experimental procedure presented in this paper is now applied to an A319 silicon-copper based aluminium alloy grade. Lost Foam Casting A319 alloy has been recently extensively introduced in the automotive industry for downsizing and lightweight objectives and cost reduction goals. It is particularly suited for in situ $\mathrm{X}$-ray tomography mechanical testing as it possesses a larger volume fraction, i.e. about $6 \%$, of coarse $\mathrm{X}$-ray visible inclusions, i.e. intermetallics and eutectic $\mathrm{Al}-\mathrm{Al}_{2} \mathrm{Cu}$.

Now that the experimental procedure has been validated in tensile loading, it will be extended to in situ fatigue testing, which will be realized with a synchrotron X-ray source. The reasons for the synchrotron X-ray tomography choice are (i) to further increase the volume fraction of visible natural markers and enhance the spatial resolution and precision of the field measurements and (ii) to achieve short scan duration, i.e. a few minutes, thanks to the high brilliance of the synchrotron X-ray source. Because in situ fatigue experiments require numerous scans to be recorded after different number of cycles and at different deformation levels for each cycle, the scan duration is indeed an important parameter to consider.

Then, in order to obtain small size specimens that better represent the cast microstructure of the cylinder heads, a casting technique is being set up to mould the specimens to their final near net shape. This should allow, in particular, studying the influence of the pore depth, which could not be analyzed in the present paper as cut specimens always have surface breaking pores.

\section{Acknowledgements}

The authors wish to thank the ANR (Agence Nationale de la Recherche) MatetPro project INDiANA for funding the study on Al-Si aluminum alloys and Jérôme Adrien from Mateis for his help and advices with the X-ray tomography experiment.

\section{References}

[1] V. Boulos, et al., 2012. Investigating performance variations of an optimized GPU-ported granulometry algorithm. In 2012 Conference on Design and 
Architectures for Signal and Image Processing (DASIP). 2012 Conference on Design and Architectures for Signal and Image Processing (DASIP). pp. 1-6.

[2] J.Y. Buffière et al., Experimental study of porosity and its relation to fatigue mechanisms of model Al-Si7-Mg0.3 cast Al alloys, Mater. Sci. Eng., A 316 (1-2) (2001) 115-126.

[3] J.Y. Buffière et al., In situ experiments with X ray tomography: an attractive tool for experimental mechanics, Exp. Mech. 50 (3) (2010) 289-305.

[4] O. Caty et al., 3D characterization of the influence of porosity on fatigue properties of a cast Al Alloy, Adv. Eng. Mater. 13 (3) (2011) 194-198.

[5] A. El Bartali et al., Surface observation and measurement techniques to study the fatigue damage micromechanisms in a duplex stainless steel, Int. J. Fatigue 31 (11-12) (2009) 2049-2055.

[6] A. El Bartali et al., Microstructural strain heterogeneities during low cycle fatigue. In 7th international conference on low cycle fatigue (LCF7), Aachen (Germany) 9-11 (2013) 34-45.

[7] M. Firsching, et al., 2010. Micro structural analysis of AlSi6Cu4 using quantitative computed tomography methods. In CD-ROM. 10th European Conference on Non-Destructive Testing, ECNDT 2010. 10, 2010, Moskau: European Federation for Non-Destructive Testing-EFNDT-, p. 4.

[8] J. Kastner et al., A comparative study of high resolution cone beam X-ray tomography and synchrotron tomography applied to Fe- and Al-alloys, NDT and E Int. 43 (7) (2010) 599-605.

[9] N. Limodin et al., Influence of closure on the 3D propagation of fatigue cracks in a nodular cast iron investigated by X-ray tomography and 3D volume correlation, Acta Mater. 58 (8) (2010) 2957-2967.
[10] N. Limodin et al., Analysis and artifact correction for volume correlation measurements using tomographic images from a laboratory X-ray source, Exp. Mech. 51 (6) (2010) 959-970.

[11] S. Roux et al., Three-dimensional image correlation from X-ray computed tomography of solid foam, Compos. A Appl. Sci. Manuf. 39 (8) (2008) $1253-$ 1265.

[12] M. Sutton et al., Advances in two-dimensional and three-dimensional computer vision, Photomechanics 77 (2000) 323-372.

[13] S. Tabibian et al., Behavior, damage and fatigue life assessment of Lost Foam Casting aluminum alloys under thermo-mechanical fatigue conditions, Procedia Eng. 2 (1) (2010) 1145-1154.

[14] S. Tabibian, Contribution to thermomechanical fatigue criteria of Lost Foam Casting aluminium alloys. PhD thesis. Ecole Centrale de Lille. (2011).

[15] D. Tolnai et al., Characterization of phases in an Al casting alloy by synchrotron tomography, Phys. Status Solidi (a) 206 (8) (2009) 1850-1854.

[16] N. Vanderesse et al., Microtomographic study and finite element analysis of the porosity harmfulness in a cast aluminium alloy, Int. J. Fatigue 33 (12) (2011) 1514-1525.

[17] O.G. Wang et al., Oxide films, pores and the fatigue lives of cast aluminum alloys, Metall. Mater. Trans. B 37 (6) (2006) 887-895.

[18] T. Zwieg, Specimen preparation for high edge retention of aluminum alloys, Ind. Heating 70 (2) (2003) 43-45. 